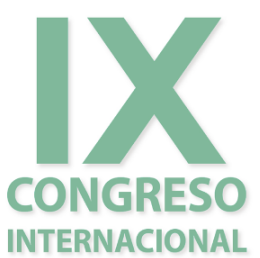
sobre Formación de Profesores de Ciencias

Bogotá, 13 a 15 de octubre de 2021 Modalidad On Line - Sincrónico
Revista Tecné, Episteme y Didaxis: TED. Año 2021. Número Extraordinario. ISSN impreso 0121-3814. E-ISSN 2323-0126. Memorias del IX Congreso Internacional Sobre Formación de Profesores de Ciencias.

Lema.

¿Cuál educación científica es deseable frente a los desafíos en nuestros contextos latinoamericanos? Implicaciones para la formación de profesores.

\title{
CONSTRUÇÃO DE CONHECIMENTOS ATRAVÉS DE PRÁTICAS EDUCATIVAS EXPERIMENTAIS NO ENSINO DE CIÊNCIAS
}

Autores. Diane Rita Rupp. Victória Santos da Silva y Rosemar Ayres dos Santos. Universidade Federal de Santa Maria, dianeritarupp@gmail.com, Universidade Federal da Fronteira Sul.victoriasantos2002.vs@gmail.com, roseayres07@gmail.com

Eixo. temático 5.

Modalidade. 1. Nível educacional. Graduação.

Resumo. A experimentação no ensino de Ciências/Biologia é importante para a compreensão e construção do saber científico escolar. Buscamos compreender e analisar de forma teórico-reflexiva quais benefícios e dificuldades essa estratégia de ensino pode proporcionar ao ensino de Ciências/Biologia e com quais objetivos vêm sendo implementada em sala de aula. Obtivemos duas categorias: "O contexto das práticas educativas experimentais", apresentando os objetivos e os resultados dessas atividades no ensino; e "Possibilidades e desafios no desenvolvimento de práticas educativas experimentais em sala de aula", abordando as limitações e desafios encontrados no ensino de Ciências/Biologia ao implementar uma prática experimental. Com a análise das pesquisas realizadas por professores em formação inicial e continuada, acreditamos que estamos caminhando para construir uma educação que possa fazer do estudante um indivíduo crítico-participativo, partilhando suas experiências.

Palavras-chave. Reflexão Crítica, Alfabetização Científico-tecnológica, Questões Sociocientíficas, Revisão Sistemática.

\section{Introdução}

As modalidades didáticas se constituem em estratégias de ensino-aprendizagem. Assim, dentre essas, a utilização da experimentação no ensino de Ciências e Biologia é importante para a compreensão e construção do saber científico escolar. Pois a experimentação inter-relaciona o aprendiz e os objetos de seu conhecimento, a teoria e a prática, une os fenômenos observados pelos seus saberes e hipóteses levantadas diante de situações desafiadoras (Lima, Júnior \& Braga, 1999). Nesse contexto, Morais e Santos (2016) identificaram vasta literatura que problematiza a experimentação em diferentes atividades práticas, como "Almeida (2001), Delizoicov, Angotti e Pernambuco (2002), Fala, Correia e Pereira (2010); Galiazzi e Gonçalves (2004); Galiazzi et al (2001); Gaspar e Monteiro (2005); Marandino, Selles e Ferreira (2009), Oliveira (2010) e Santos, (2008, 2009)" (p.167).

Desse modo, na literatura há indicativos que as atividades práticas educativas experimentais, quando conduzidas de maneira investigativa permite ao estudante desenvolver um conhecimento científico, despertando interesse e curiosidade podendo relacionar o conhecimento construído em sala de aula com sua realidade vivida. Concordando com Rosito (2008), quando refere que as atividades experimentais desempenham papel fundamental na construção do conhecimento, pois possibilita ao estudante uma aproximação do trabalho científico e melhor compreensão dos mesmos. Portanto, quando bem planejada, uma aula com essas atividades pode se tornar mais atraente e produtiva, possibilitando uma maior interação professor/estudante. Nessa perspectiva, muitos professores apresentam dificuldades para desenvolver práticas educativas experimentais. E, isso pode ocorrer, entre outras possibilidades, pela falta de preparo, podem não ter tido uma formação adequada para uso de diferentes metodologias que qualificam ainda mais o ensino em sala de aula, sentindo insegurança. Na intenção de superar 

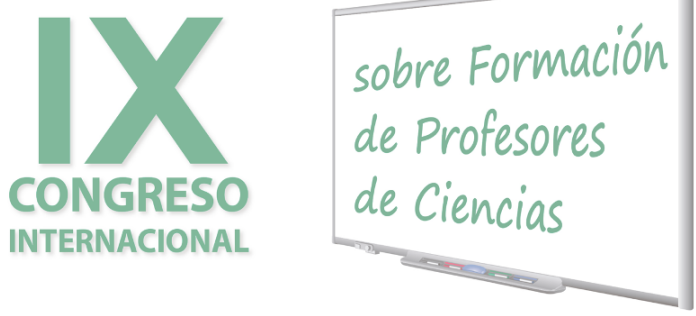

Bogotá, 13 a 15 de octubre de 2021 Modalidad On Line - Sincrónico
Revista Tecné, Episteme y Didaxis: TED. Año 2021. Número Extraordinario. ISSN impreso 0121-3814. E-ISSN 2323-0126. Memorias del IX Congreso Internacional Sobre Formación de Profesores de Ciencias.

Lema.

¿Cuál educación científica es deseable frente a los desafíos en nuestros contextos latinoamericanos? Implicaciones para la formación de profesores.

essa falta de preparo, identificamos a necessidade de uma formação continuada que auxilie o trabalho pedagógico com diferentes perspectivas teórico-metodológicas, entre as quais a experimentação.

Dessa forma, trabalhar com a experimentação de forma dialógico-problematizadora permite ao professor promover a reflexão sobre a prática educativa, gerando melhorias na qualidade do ensino, possibilitando ao estudante tornar-se sujeito crítico atuando de forma dinâmica e contribuindo para construção de seu conhecimento.

Partindo dessa compreensão, buscamos compreender e analisar de forma teórico-reflexiva quais benefícios e dificuldades dessa estratégia de ensino pode proporcionar para ao ensino de Ciências/Biologia e com quais objetivos vêm sendo implementada em sala de aula. Assim, investigamos: como e com quais objetivos a modalidade didática experimentação vem sendo desenvolvida no Ensino de Ciências e Biologia a partir da análise das pesquisas publicados na REnBio - Revista de Ensino de Biologia? Nesse sentido, investigamos artigos relacionados com a temática experimentação no ensino de Ciências e Biologia, como essa vem sendo trabalhada na Educação Básica.

\section{Referencial teórico}

As práticas educativas experimentais têm sido reconhecidas como uma modalidade didática com papel importante no ensino de Ciências e Biologia. Hodson (1994) define estas atividades como sendo qualquer trabalho em que os estudantes estejam ativo-participantes, manipulando, investigando e solucionando problemas como, por exemplo, debate em grupo, resolução de problemas, desenhos, colagens, construções de maquetes, jogos didáticos, atividades interativas com uso de computadores, saídas de campo ou uma encenação e teatro (Rosito, 2008).

Já, Miranda (2017), ao caracterizar o ensino de Ciências/Biologia nas escolas como sendo "reducionista, prescritivo e memorização de termos e conceitos biológicos, além de utilizar do método científico na abordagem de determinados conteúdos, o que constitui um ensino limitado aos livros didáticos" (p. 23), considera que a atividade experimental é "fundamental no ensino de Biologia e parte constitutiva do ensino desta [...] sendo ela um método de ensino com rico potencial de aprendizagem por auxiliar os estudantes a aprender os conceitos com mais clareza e objetividade ao proporcionar a aplicação ou observação prática e imediata dos conteúdos que estão sendo aprendidos" (p. 23).

Nesse âmbito, outra observação é o fato da utilização genérica do termo experimento é aplicada, na maioria das vezes, na perspectiva de confirmar leis e teorias sem a possibilidade de construção de conhecimento diante das situações diferentes do já esperado, não sendo associado a situações reais pertencentes às vivências do estudante. Nesse contexto, há a necessidade de mudança dessa visão equivocada, há a necessidade dos experimentos realizados dentro do ambiente escolar ser caracterizados em atividades de investigação de ideias e concepções do estudante, para que ele possa explorar seu próprio conhecimento, compreender o que está sendo aprendido e relacionar com as atividades realizadas, considerando a discussão teórica sobre o que está sendo investigado.

Dessa forma, nos valemos de Freire (1996), quando adverte ser errado separar prática da teoria, o pensamento da ação. Pois entendemos que "a realização de experimentos nas aulas de Ciências representa uma excelente ferramenta para que o aluno faça a experimentação do conteúdo e possa estabelecer a dinâmica e indissociável relação entre teoria e prática" (Bevilacqua \& Coutinho-Silva, 2007, p. 85). Nesse sentido, com o desenvolvimento de atividades investigativas a dificuldade apresentada pelo estudante em relacionar a teoria apreendida em sala de aula com o mundo vivido pode ser suprimida, despertando nele a chamada curiosidade epistemológica, indispensável na produção do conhecimento (Freire, 1996). 

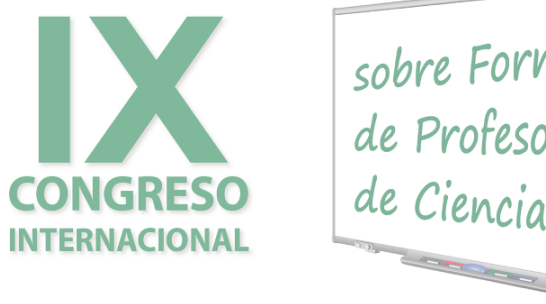

Bogotá, 13 a 15 de octubre de 2021 Modalidad On Line - Sincrónico
Revista Tecné, Episteme y Didaxis: TED. Año 2021. Número Extraordinario. ISSN impreso 0121-3814. E-ISSN 2323-0126. Memorias del IX Congreso Internacional Sobre Formación de Profesores de Ciencias.

Lema.

¿Cuál educación científica es deseable frente a los desafíos en nuestros contextos latinoamericanos? Implicaciones para la formación de profesores.

Nessa perspectiva, além da formação inicial e continuada ser considerada para uma mudança de visão quanto aos reais objetivos de práticas educativas experimentais de caráter escolar, também, há necessidade de incentivar os estudantes a pesquisar, ler e escrever mais a cada aula teórico-prática, antes e após a experimentação, para que reflitam sobre o conhecimento construído. Não basta que apenas realizem a atividade prática ou acompanhem uma demonstração feita pelo professor, uma vez que a compreensão sobre o fenômeno estudado se dá na mediação e não, apenas, pela observação (Silva \& Zanon, 2000).

Logo, considerando que essas práticas podem ser organizadas de formas diversas, desde estratégias que focalizam a simples ilustração ou verificação de leis e teorias até aquelas que estimulam a criatividade e proporcionam condições para refletir e rever suas ideias a respeito dos fenômenos científicos, situando-se em atividades de demonstração, de verificação e de investigação, como elencou Oliveira (2010), apoiada em Araújo e Abib (2003).

Dessa forma, diante das possibilidades de abordagem das práticas educativas experimentais e das contribuições dessas para o ensino de Ciências, cabe ao professor compreendê-las e utilizá-las conforme os objetivos que associa a essa utilização. Considerando sempre quem é seu sujeito de aprendizagem e a que contexto social ele pertence, para que o ensinoaprendizagem, de fato, ocorra e que ele tenha sua curiosidade epistemológica aguçada, o seu querer aprender, critério fundamental para o verdadeiro aprender.

\section{Metodologia}

Essa pesquisa configura-se em qualitativa de cunho bibliográfico (Gil, 2008). Metodologicamente, seguimos a Análise Textual Discursiva (ATD) (Moraes, 2003), constituída por etapas: 1) unitarização; 2) categorização; e 3) comunicação; base para a auto-organização da pesquisa. Desse modo, o corpus de análise esteve constituído do conjunto de artigos publicados na Revista Eletrônica de Ensino de Biologia, a REnBio, que abordam práticas educativas experimentais, considerando as publicações dos trabalhos apresentados no Encontro Nacional de Ensino de Biologia, ENEBio.

Para a seleção do corpus para a análise utilizamos como critério os artigos conter no título e/ou palavras-chaves e/ou resumo, uma das expressões "atividades práticas", "experimentação", "experimento". Assim, identificados 88 artigos que abordavam e discutiam experimentação no ensino de Ciências de modo geral. Refizemos a seleção identificando as pesquisas focalizassem em práticas educativas experimentais implementadas em sala de aula, desse modo, identificamos 29 , os quais foram identificados como A1, A2, ..., A29. Realizamos a unitarização do corpus de análise na busca de núcleos de sentido, da qual resultou em 103, com base no referencial teórico-metodológico, assim como, considerando nossos objetivos de pesquisa (re) discutir como e com quais objetivos a experimentação nas aulas de Ciências e Biologia está sendo implementado em salas de aulas potencializar o ensino?

Nesse âmbito, a segunda etapa da ATD foi a categorização, em que obtivemos duas categorias emergentes de acordo com unidades de sentido, relacionadas a práticas educativas experimentais. Por fim, realizamos a terceira etapa, a descrição e interpretação dos dados que foram obtidos, em uma auto-organização. Ou seja, foi possível realizar a contextualização utilizando referencial teórico, fazendo uma análise crítica sobre a concepção e relevância dos experimentos em sala de aula. Assim, segue no próximo item a discussão das categorias, a comunicação. 


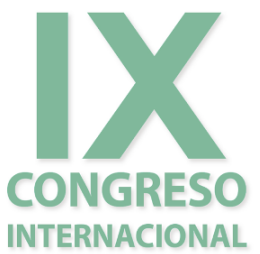
sobre Formación de Profesores de Ciencias

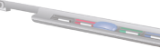

Bogotá, 13 a 15 de octubre de 2021 Modalidad On Line - Sincrónico
Revista Tecné, Episteme y Didaxis: TED. Año 2021. Número Extraordinario. ISSN impreso 0121-3814. E-ISSN 2323-0126. Memorias del IX Congreso Internacional Sobre Formación de Profesores de Ciencias.

Lema.

¿Cuál educación científica es deseable frente a los desafíos en nuestros contextos latinoamericanos? Implicaciones para la formación de profesores.

\section{Resultados e discussão}

\section{O contexto das práticas educativas experimentais}

Essa categoria resulta da análise dos objetivos, resultados, estratégia que as atividades práticas experimentais analisadas apresentam ao serem implementadas no ensino, obtivemos 45 núcleos de sentido de um total de 103.

Desse modo, a partir da análise dos núcleos sentido que compõem essa categoria foi possível identificarmos, amparados em Hodson (1994), Praia, Cachapuz e Gil-Pérez (2002), Gibin e Souza Filho (2016), Morais e Santos (2016) Miranda (2017), Wyzykowski, Güllich e Araújo (2016) e Galiazzi et al. (2001), que os experimentos precisam ser investigativos e reflexivos, permitindo aos estudantes entenderem o verdadeiro sentido da realização do experimento que está sendo feito e adquirem novos conhecimentos estimulando a criatividade, como caracteriza o núcleo de sentido: "A investigação como método nos processos de ensino e aprendizagem tem como foco estimular o estudo e a curiosidade pelo desconhecido, incitar a problematização de diferentes situações do cotidiano [...]" (A3, Schirmer, Bielaski \& Michel, p. 5077).

Outra questão que percebemos foi que as atividades experimentais podem ser desenvolvidas com diferentes objetivos e fornecendo, desse modo, diferentes contribuições para aprendizagem do estudante, estimulando sua criatividade e proporcionando condições para refletir revendo suas ideias e concepções prévias. No intuito de desenvolver, por exemplo, a capacidade de trabalho em grupo fazendo uma interação maior entre professor/estudante e estudante/estudante, resolvendo situações-problema juntos, desenvolvem a capacidade de registro, propondo hipótese de suas observações e anotações da atividade realizada levando à construção do saber científico. "A escola precisa ter como objetivo não apenas a transmissão unilateral de conhecimentos científicos, mas também visar modelos que permitam o raciocínio e a investigação para instigar nos alunos uma posição crítica e reflexiva sobre os conteúdos abordados". (A2, Macedo \& Ursi, p. 2724).

Muitos dos núcleos de sentido que compõem essa categoria mostram a compreensão de atividades práticas experimentais para comprovar teorias e conceitos. Mas, a maioria delas atribuiu um caráter motivador, sendo importante para despertar a atenção do estudante, prestar atenção na aula e melhor compreender os conteúdos. Nelas os estudantes participavam de maneira ativa do procedimento fazendo uma discussão e análise, o que possibilitou a interpretação dos resultados relacionando com fenômenos do cotidiano e das aulas. Mas para isso é necessário que o professor envolva os estudantes na atividade, por exemplo, solicitando registros.

Assim, percebemos com a análise que para que esse tipo de atividade seja efetivo ao ensino é necessário fazer um levantamento dos conhecimentos prévios dos estudantes antes da atividade, sendo que durante a realização chamar atenção para a atividade de forma dialógico-problematizadora, permitindo o estudante ser mais ativo no processo de ensino participando das etapas da investigação propondo resolução dos problemas e levantando hipóteses em que o professor se torna o mediador do conhecimento.

\section{Possibilidades e desafios no desenvolvimento de práticas educativas experimentais em sala de aula}

Essa categoria resulta de nossa constatação das dificuldades que muitos professores têm ao utilizar uma metodologia considerada diferente em sala de aula, nessa obtivemos 58 núcleos de sentido. Pois os professores são sabedores desta metodologia e discutem muito sobre as contribuições, entendem que as: "atividades experimentais podem ser utilizadas como um complemento importante a outras modalidades de ensino, como as aulas exclusivamente teóricas em sala de aula" (A8, Rocha, Pinto \& Araújo, 2014, p. 396). 

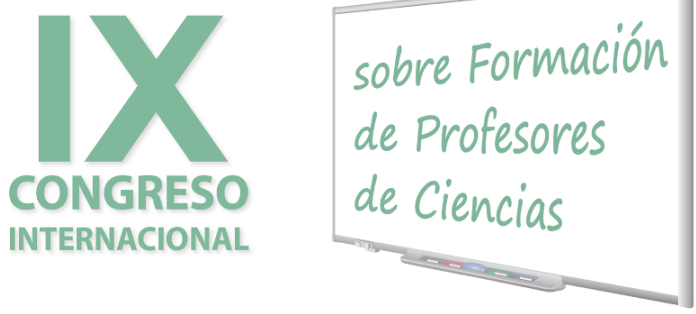

Bogotá, 13 a 15 de octubre de 2021 Modalidad On Line - Sincrónico
Revista Tecné, Episteme y Didaxis: TED. Año 2021. Número Extraordinario. ISSN impreso 0121-3814. E-ISSN 2323-0126. Memorias del IX Congreso Internacional Sobre Formación de Profesores de Ciencias.

Lema.

¿Cuál educación científica es deseable frente a los desafíos en nuestros contextos latinoamericanos? Implicaciones para la formación de profesores.

Quanto às limitações que, muitas vezes, acompanham a experimentação no contexto escolar, podemos elencar as mais encontradas a partir da análise dos núcleos de sentido: as quais são: dificuldade de compreensão do conteúdo por parte dos estudantes, não os recordando no momento da atividade, falta de preparo dos professores em utilizar novas metodologias, ausência de local e escassez de materiais e equipamentos, entre outras. Sendo um dos maiores desafios do uso de aulas práticas experimentais é construir uma relação entre o conteúdo e as vivências dos estudantes

Outra questão observada em nossa investigação foi de muitos dos artigos analisados, mesmo atendendo ao critério de seleção, fugiam do nosso enfoque principal, os quais abordavam investigação de eficácia dessa metodologia ou relatos de experiências bem como modelos didáticos. Desse modo, através da análise ficam evidentes que as aulas de Ciências e Biologia denominadas como tradicionais, ainda presentes em alguns contextos, têm levado os estudantes a decorar teorias, fórmulas, enunciados, sem fazer com que eles discutam sobre os fenômenos, estabelecendo relações com seu mundo vivido.

Percebemos que alguns experimentos realizados em sala de aula ainda tem a concepção identificada por Güillich e Silva (2013, p. 159) de Ciência Reproducionista, "[...] ideia de que a experimentação é meramente um conjunto de procedimentos a serem repetidos como forma de comprovação de teorias [...]". O que percebemos em A4 ao referir, apoiada em Fagundes (2007), que a prática unicamente tradicional ainda persiste em muitas escolas e que "alguns professores justificam suas aulas, basicamente conteudistas, como uma consequência das dificuldades cotidianas, ou seja, da ausência de local apropriado (o amedrontador laboratório) e a escassez de material e equipamentos adequados" (A 4, Boszko, Santos \& Venzke, p. 1025). Nesse sentido, notamos positivamente, através da análise, que a maioria das atividades desenvolvidas não são de abordagem tradicional, orientadas por um roteiro pronto como se fosse uma "receita" a ser seguida. Sem questionar, sem perguntar, sem levantar possiveis hipóteses.

Observamos, também, que as atividades experimentais ainda são um desafio para os professores para tornar as aulas prazerosas levando o estudante a desenvolver o conhecimento científico escolar. Nessa perspectiva, relacionando a falta de participação e interesse dele ao desenvolver uma atividade investigativa e a expectativa de dinamizar o ensino, tornando-o mais atrativo vem sendo discutido há muito tempo entre as propostas de inovação dos currículos escolares (Carmo \& Schimin, 2008). Também, comparecem núcleos de sentido que mostram que os professores sabem do quanto importante é, mas não implementam atividades experimentais em sala de aula.

Conforme artigos analisados as atividades experimentais são bastante discutidas por professores em relação as suas finalidades e abordagens isso porque trabalhar com uma modalidade didática como ferramenta pedagógica ajuda o professor a refletir sobre sua prática e no educar pela pesquisa promovendo melhoria na qualidade do ensino e possibilita ao aluno tornar-se sujeito crítico atuando de forma dinâmica e contribuindo para construção de conhecimentos

Dessa forma, nessa análise foi possivel observar a relevância que essa metodologia tem no ensino e de como é pouco discutida entre pesquisadores da área, tendo em vista o baixo número de artigos se referirem a essa no total de artigos presentes na REnBio. Demonstrando que ainda existem muitas limitações no ensino de Ciências e Biologia, predominando outras ênfases como, por exemplo, a que considera apenas o "conteúdo", denominada de conteudista. Entretanto, entendemos que "através da prática educativa de experimentação em sala de aula, [...] o conteúdo proposto se torna mais dinâmico, flexibilizando o ensino [...], fazendo com que o estudante desenvolva um senso crítico e participativo, elaborando ideias e questionamentos e promovendo sua formação consistente como cidadão" (Marsango, Mergen \& Santos, p. 98). 


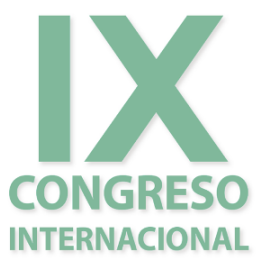
sobre Formación de Profesores de Ciencias

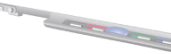

Bogotá, 13 a 15 de octubre de 2021 Modalidad On Line - Sincrónico
Revista Tecné, Episteme y Didaxis: TED. Año 2021. Número Extraordinario. ISSN impreso 0121-3814. E-ISSN 2323-0126. Memorias del IX Congreso Internacional Sobre Formación de Profesores de Ciencias.

Lema.

¿Cuál educación científica es deseable frente a los desafíos en nuestros contextos latinoamericanos? Implicaciones para la formación de profesores.

\section{Considerações}

No presente estudo tínhamos, inicialmente, a expectativa de encontrar um número maior de trabalhos que abordassem a temática relacionada à utilização de experimentação no ensino de Ciências e Biologia. A partir da análise foi possível perceber que os professores sabem da importância da experimentação nas aulas de Ciências e Biologia, mas não utilizam, pois no decorrer de sua docência encontram dificuldades como as, anteriormente, referidas.

Contudo, foi possível verificarmos que não é fácil propor uma aula com metodologia diferenciada, pois romper o denominado ensino tradicional vigente no ensino se torna um complicador. Porém, com análise das pesquisas realizadas por professores, em formação inicial e continuada, envolvidos nesta prática de ensino das aulas experimentais, nos faz acreditar que estamos caminhando para construir uma educação que possa fazer do estudante um indivíduo participativo, podendo refletir sobre e partilhar de suas experiências.

\section{Referências bibliográficas}

Carmo, S., \& Schimin, E. S (2008). O ensino da biologia através da experimentação. Disponível em: < http://www.diaadiaeducacao.pr.gov.br/portals/pde/arquivos/1085-4.pdf>.

Freire, P. (1996). Pedagogia da Autonomia: saberes necessários a prática educativa. São Paulo: Paz e Terra.

Galiazzi, M. C. et al. (2001). Objetivos das atividades experimentais no ensino médio: a pesquisa coletiva como modo de formação de professores de ciências. Ciência \& Educação, 7(2), 249-263.

Gibin, G. B., \& Souza Filho, M. P. (2016). Atividades experimentais investigativas em Física e Química: uma abordagem para o Ensino Médio. 1. São Paulo: Editora Livraria da Física.

Gil, A. C. (2008). Métodos e técnicas de pesquisa social. 6. ed. São Paulo: Atlas.

Güllich, R. I. C, \& Silva, L. H. A. (2013) O enredo da experimentação no livro didático: construção de conhecimentos ou reprodução de teorias e verdades científicas? Ensaio, 15(2), 155-167.

Hodson, D. (1994). Hacia um enfoque más crítico del trabajo de laboratorio. Enseñanza de las Ciencias, 12(13), 299-313.

Lima, M.E.C., Júnior, O.G.A., \& Braga, S.M (1999). Aprender Ciências: um mundo de materiais. Belo Horizonte: UFMG.

Marsango, D., Mergen, A., \& Santos, R. A. (2019). Lei do farol baixo e o consumo de energia: possibilidades de práticas educativas em sala de aula. Ciências \& Ideias, 10(1), 89-100.

Miranda, E. S. A. (2017). A experimentação no ensino de Biologia: contribuições da teoria do ensino desenvolvimental para a formação no pensamento teórico. Dissertação Mestrado em Educação, Universidade Federal de Goiás.

Moraes, R. (2003). Uma tempestade de luz: a compreensão possibilitada pela análise textual discursiva. Ciência \& Educação, 9(2), 191-211.

Morais, V. C. S., \& Santos, A. B. (2016). Implicações do uso de atividades experimentais no ensino de Biologia na escola pública. Investigações em Ensino de Ciências, 21(1), 166-181.

Oliveira, J. R. S. (2010). Contribuições e abordagens das atividades experimentais no ensino de ciências: reunindo elementos para a prática docente. Acta Scientiae, 12(1), 139 - 153. 

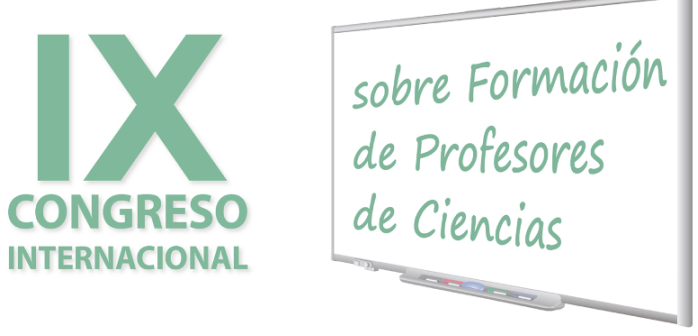

Bogotá, 13 a 15 de octubre de 2021 Modalidad On Line - Sincrónico
Revista Tecné, Episteme y Didaxis: TED. Año 2021. Número Extraordinario. ISSN impreso 0121-3814. E-ISSN 2323-0126. Memorias del IX Congreso Internacional Sobre Formación de Profesores de Ciencias.

Lema.

¿Cuál educación científica es deseable frente a los desafíos en nuestros contextos latinoamericanos? Implicaciones para la formación de profesores.

Praia, J., Cachapuz, A., \& Gil-Pérez, D. (2002). A hipótese e a experiência científica em educação em ciência: contributos para uma reorientação epistemológica. Ciência \& Educação, 8(2), 253-262.

Rosito, B. A. (2008). O Ensino de Ciências e a Experimentação. In: Moraes, R. Construtivismo e Ensino de Ciências. Porto Alegre: EDIPUCRS.

Silva, L. H. A., \& Zanon, L.B. (2000). Experimentação no ensino de ciências. In: Schnetzer, R. P., \& Aragão, R. M. R. (Orgs.) Ensino de Ciências: fundamentos e abordagens. Campinas: V Gráfica. 120-153.

Wyzykowski, T., Güllich, R. I. C., \& Araújo, M. C. P. (2016). Compreendendo a experimentação em Ciências: entre o discurso e a prática. Revista de Educación en Biología, 19(1), 35-53. 